\title{
A NOVEL FUZZY MULTI-CRITERIA DECISION-MAKING METHODOLOGY BASED UPON THE SPHERICAL FUZZY SETS FOR STABILIZER SELECTION OF CRUISE SHIPS
}

UDC 629.5.015.12:629.541.42:629.5.025.22

Original scientific paper

\section{Summary}

In recent years, studies for the development of cruise shipbuilding and design industry is known to be performed by many countries. It is obvious that cruise ships should be equipped with features that facilitate the mobility of the crew in different sea states by providing passenger comfort in long cruise conditions. At this point, cruise ships which require great cost and experience should be evaluated from different perspectives. In this study, the selection of stabilizer system which directly affects many criteria such as comfort, safety and speed in cruise ships is discussed. Stabilizer system alternatives and the criteria determined for these alternatives have been established by literature review. Extension of TOPSIS method with interval-valued spherical fuzzy sets proposed to determine the most effective stabilizing system alternative for cruise ships. The results obtained indicate the Activated fins as the most effective alternative.

Key words: $\quad$ Cruise ships; Spherical Fuzzy Sets; Decision Making; TOPSIS

\section{Introduction}

The comfort of crew and passengers is of paramount importance to cruise ships. In addition to this, it is known that people's mobility is directly affected by ship motions. At this point, it is stated that various types of devices are used to stabilize the roll motion which is critical in ship motions [1]. Roll stabilization systems are evaluated in two different groups as active and passive. Active systems require a control system and are referred to as activated fins, active anti-roll tanks and gyroscope stabilizers. The passive systems are fixed mechanisms like bilge keel, passive anti-rolling tanks, fixed fins, and passive moving weight systems [2-3]. The first anti-rolling devices are bilge keels. After these systems, anti-rolling tank systems have been designed and used for roll damping of many types of ships [4-5]. Specifically, different types of active stabilizing systems are used in passenger ships, yachts and special purpose ships and in many studies, it is emphasized that these systems have a positive effect on the comfort and performance of the ships. Perez and Steinmann (2009). analysed the performance of gyrostabilisers to decrease the roll motion of ships [6]. Lee et al. 
(2011) evaluated the performance of fin stabilizers for roll stabilization of cruise ships in regular waves [7]. Kim and Kim (2011) examined the roll and/or pitch motions of a cruise ship in a moderate sea state and suggested an effective control algorithm to reduce these motions for a cruise ship with stabilizing fins [8]. Lee et al. (2012). suggested the fins and pod propellers for the roll stabilization of cruise ships and analysed the effects of these devices [9]. Kim and Kim (2014). examined the factors affecting passenger comfort for cruise ships and suggested the stabilizing fins to improve passenger comfort [10]. Ye et al. (2019). emphasized the rapid development of cruise industry and they interpreted the characteristics of cruise ships related to speed, safety and comfort [11]

As stated above, the choice of stabilizer system is an issue where many criteria and alternatives should be considered. The determination of the most appropriate stabilizer system for ships, each with different advantages and disadvantages, is essentially a multi-criteria decision-making problem. At this point, it is thought that the selection made by taking the opinions of experts in the field will respond more effectively to the expectations. However, there are no comprehensive studies based on multi-criteria decision-making methods in the maritime industry. Kafalı and Özkök [12] used a fuzzy AHP technique for the shipyard selection process and determined the most significant criteria/sub-criteria for this problem. Sellers and Martin [13] presented the comprehensive procedure for different roll stabilizing systems and evaluated the advantages and disadvantages of these systems. Demirel et al. [14] examined the different type of roll stabilizers for fishing vessels and suggested a fuzzy AHP and ELECTRE method for determination the most suitable one. In this study, the choice of stabilizer system for cruise ships is determined as a multi - criteria decision making problem. The relationship between the alternatives and the criteria was evaluated by experts. In addition to this perspective, the issue is evaluated by experts in different positions in the maritime sector and is important to decide with the data obtained interval-valued spherical fuzzy sets.

The continuation of this study is organized as follows: In Section 2, the methodology of spherical fuzzy sets is revealed. Section 3 describes the structure of TOPSIS method with interval-valued spherical fuzzy sets. Section 4 explains the assessments of the real case application for cruise ships using spherical fuzzy sets. Finally, evaluations of the results are expressed in Section 5.

\section{Spherical Fuzzy sets}

Intuitive and Pythagorean fuzzy functions comprise the parameters of membership, nonmembership and hesitation. These parameters can be determined by $x_{i}=1-\mu_{i}-v_{i}$ and $\pi_{\tilde{p}}=\sqrt{1-\mu_{\tilde{p}}^{2}-v_{\tilde{p}}^{2}}$ formulas respectively. Truthiness, falsity and indeterminacy are expressed as three parameters of Neutrosophic membership functions. These parameters must be between 0 and 3 as the total value, as well as the value of each parameter should be independently between 0 and 1 . In spherical fuzzy sets, the squared sum of membership, nonmembership and hesitation parameters must be between 0 and also 1, while each independently defined between 0 and 1 . As a result of these two conditions, the shape of the new fuzzy sets is formed. Using a spherical fuzzy set provides a wider decision-making environment as well as independent decision-making by decision-makers (Gong et al., 2016; Ullah et al., 2018; Gundogdu and Kahraman, 2019 a,b,c; Kahraman et al. 2019; ). The positive aspects of other fuzzy set extensions show the advantage of spherical fuzzy sets as a unique theory.

The main purpose of the global fuzzy sets (SFS) is to allow decision makers to generalize the extensions of other fuzzy sets by defining a membership function on a spherical 
methodology based upon the spherical fuzzy sets for stabilizer selection of cruise ships

surface and assigning the parameters of this membership function independently to a larger domain. SFS is a synthesis of Pythagoras fuzzy sets (PFS) and Neutrosophic sets (NS) (Gündoğdu and Kahraman, 2019 a, b, c).

\section{Extension of TOPSIS method with interval-valued spherical fuzzy sets}

The TOPSIS method is firstly suggested by Hwang and Yoon (1981). The basic structure of this method is that the selected alternative should have the shortest distance from the positive ideal solution and the farthest distance from the negative ideal solution (Hwang and Yoon, 1981). A method has been proposed in which alternative TOPSIS, the weights of alternatives, criteria and ratings of alternatives are evaluated with linguistic variables represented by fuzzy numbers to deal with the deficiency in traditional TOPSIS (Ertuğrul and Karakaşoğlu, 2008). In this paper, an extension of the TOPSIS method is presented (Gündoğdu, and Kahraman, 2019 a).

This section refers to the use of distance measurement, arithmetic operations, aggregation and defuzzification operations (Peng, and Yang 2016a,b; Gong et al. 2016; Gundogdu and Kahraman, 2019a; Ashraf et al., 2018; Ashraf et al., 2019a,b,c,d). The related algorithm can be revealed as follows:

MCDM problems expressed as a decision matrix that specifies the values of all alternatives for each criterion under interval-valued spherical fuzzy environment. Allow $X=\left\{x_{1}, x_{2}, \ldots \ldots, x_{m}\right\}(m \geq 2)$ to be a discrete $m$ applicable alternative set and $C=\left\{C_{1}, C_{2}, \ldots . ., C_{n}\right\}$ was a finite set of criteria, and $w=\left\{w_{1}, w_{2}, \ldots . ., w_{n}\right\}$ will be the weight vector of all criteria satisfying $0 \leq w_{j} \leq 1$ and $\sum_{j=1}^{n} w_{j}=1$ (Gündoğdu, and Kahraman, 2019a).

Table 1 Linguistic terms and their corresponding interval-valued spherical fuzzy numbers (Gündoğdu, and Kahraman, 2019a)

Linguistic terms

$$
\left(\left[\mu_{i j}^{L}(u), \mu_{i j}^{U}(u)\right],\left[v_{i j}^{L}(u), v_{i j}^{U}(u)\right],\left[\pi_{i j}^{L}(u), \pi_{i j}^{U}(u)\right]\right)
$$

Absolutely more Importance (AMI) $\quad([0.85,0.95],[0.1,0.15],[0.05,0.15])$

Very High Importance (VHI)

$([0.75,0.85],[0.15,0.2],[0.15,0.2])$

High Importance (HI)

$$
([0.65,0.75],[0.2,0.25],[0.2,0.25])
$$

Slightly More Importance (SMI)

$$
([0.55,0.65],[0.25,0.3],[0.25,0.3])
$$

Equally Importance (EI)

$([0.5,0.55],[0.45,0.55],[0.3,0.4])$

Slightly Low Importance (SLI)

$([0.25,0.35],[0.55,0.65],[0.25,0.3])$

Low Importance (LI)

Very Low Importance (VLI)

$$
([0.15,0.2],[0.75,0.85],[0.15,0.2])
$$

Absolutely Low Importance (ALI)

Step 1: The scale shown in Table 1 used for data input. DMs can prefer intermediate values instead of given language terms. Therefore, DM assessments for weight criteria are summed, linguistic terms of DMs are used and decision matrices are filled.

Creating a decision matrix: let $C_{j}\left(X_{i}\right)=\left(\left[\mu_{i j}^{L}(u), \mu_{i j}^{U}(u)\right],\left[v_{i j}^{L}(u), v_{i j}^{U}(u)\right],\left[\pi_{i j}^{L}(u), \pi_{i j}^{U}(u)\right]\right)$ show the evaluation of each alternative $X_{i}(i=1,2, \ldots . ., m)$ with respect to each criterion 
$C_{j}(j=1,2, \ldots \ldots, n)$. Let $D=\left(C_{j}\left(X_{i}\right)\right)_{m x n}$ be a spherical fuzzy decision matrix. Then the decision matrix $D=\left(C_{j}\left(X_{i}\right)\right)_{m \times n}$ created as in the following equation.

$$
D=\left(C_{j}\left(X_{i}\right)\right)_{m \times n}=\left[\begin{array}{ccc}
\left(\left[\mu_{11}^{L}(u), \mu_{11}^{U}(u)\right],\left[v_{11}^{L}(u), v_{11}^{U}(u)\right],\left[\pi_{11}^{L}(u), \pi_{11}^{U}(u)\right]\right) & \ldots & \left(\left[\mu_{1 n}^{L}(u), \mu_{1 n}^{U}(u)\right],\left[v_{1 n}^{L}(u), v_{1 n}^{U}(u)\right],\left[\pi_{1 n}^{L}(u), \pi_{1 n}^{U}(u)\right]\right) \\
\left(\left[\mu_{22}^{L}(u), \mu_{22}^{U}(u)\right],\left[v_{22}^{L}(u), v_{22}^{U}(u)\right],\left[\pi_{22}^{L}(u), \pi_{22}^{U}(u)\right]\right) & \ldots & \left(\left[\mu_{2 n}^{L}(u), \mu_{2 n}^{U}(u)\right],\left[v_{2 n}^{L}(u), v_{2 n}^{U}(u)\right],\left[\pi_{2 n}^{L}(u), \pi_{2 n}^{U}(u)\right]\right) \\
\ldots \ldots & \ldots . & \ldots . \\
\left(\left[\mu_{m 1}^{L}(u), \mu_{m 1}^{U}(u)\right],\left[v_{m 1}^{L}(u), v_{m 1}^{U}(u)\right],\left[\pi_{m 1}^{L}(u), \pi_{m 1}^{U}(u)\right]\right) & \ldots . . & \left(\left[\mu_{m n}^{L}(u), \mu_{m n}^{U}(u)\right],\left[v_{m n}^{L}(u), v_{m n}^{U}(u)\right],\left[\pi_{m n}^{L}(u), \pi_{m n}^{U}(u)\right]\right)
\end{array}\right]
$$

Step 2: The Interval Valued Spherical Weighted Arithmetic Mean (IVSWAM) operator adopted to create the decision matrix.

$$
\begin{aligned}
& \operatorname{SWAM}_{w}\left(\tilde{A}_{S 1}, \ldots \ldots, \tilde{A}_{S n}\right)=w_{1} \tilde{A}_{S 1}+w_{2} \tilde{A}_{S 2}+\ldots \ldots \ldots \ldots .+w_{n} \tilde{A}_{S n} \\
& =\left\{\left[1-\prod_{i=1}^{n}\left(1-\mu_{\tilde{A}_{S i}}^{2}\right)^{w_{i}}\right]^{1 / 2}, \prod_{i=1}^{n} v_{\tilde{A}_{S i}}^{w_{i}}\left[\prod_{i=1}^{n}\left(1-\mu_{\tilde{A}_{S i}}^{2}\right)^{w_{i}}-\prod_{i=1}^{n}\left(1-\mu_{\tilde{A}_{S i}}^{2}-\pi_{\tilde{A}_{S i}}^{2}\right)^{w_{i}}\right]^{1 / 2}\right\}
\end{aligned}
$$

Step 3: Generate the weighted interval-valued spherical fuzzy decision matrix.

After determining the weights of the criteria and the scores of the alternatives, the weighted interval-valued spherical fuzzy decision matrix formed using the $D=\left(C_{j}\left(X_{i w}\right)\right)_{m x n}$ equation;

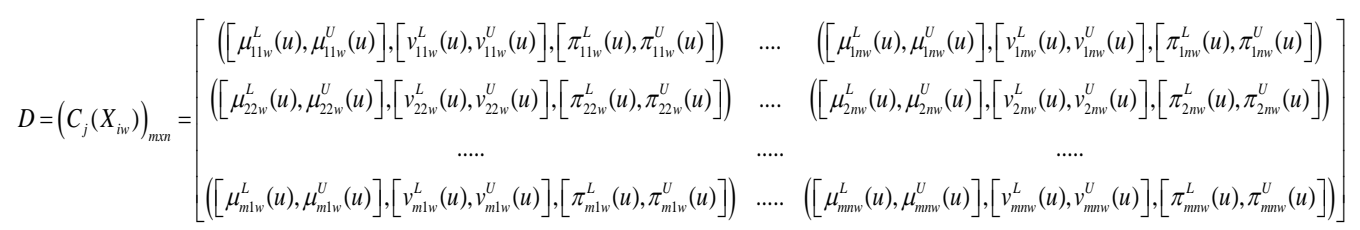

Step 4: Defuzzify the weighted interval-valued spherical fuzzy decision matrix generated using the $S\left(C_{j}\left(X_{i w}\right)\right)$ equation;

$$
S\left(C_{j}\left(X_{i w}\right)\right)=\frac{\left(\mu_{i j w}^{L}(u)\right)^{2}+\left(\mu_{i j w}^{U}(u)\right)^{2}-\left(v_{i j w}^{L}(u)\right)^{2}-\left(v_{i j w}^{U}(u)\right)^{2}-\left(\frac{\pi_{i j w}^{L}(u)}{2}\right)^{2}-\left(\frac{\pi_{i j w}^{U}(u)}{2}\right)^{2}}{2}
$$

Step 5: The Interval-valued Spherical Fuzzy Positive Ideal Solution (IVSF-PIS) and the Interval-valued Spherical Fuzzy Negative Ideal Solution (IVSF-NIS) identified based on the values obtained in step 4 .

The IVSF-PIS given by $X^{*}$ :

$$
X^{*}=\left\{C_{j}, \max _{i}<S\left(C_{j}\left(X_{i w}\right)\right)>j=1,2 \ldots \ldots n\right\}
$$

or

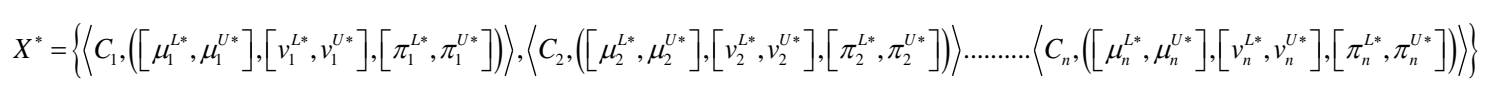

The IVSF-NIS given by $X^{-}$: 


$$
X^{-}=\left\{C_{j}, \min _{i}<S\left(C_{j}\left(X_{i w}\right)\right)>j=1,2 \ldots \ldots n\right\}
$$

or

$$
X^{-}=\left\{\left\langle C_{1},\left(\left[\mu_{1}^{L-}, \mu_{1}^{U-}\right],\left[v_{1}^{L-}, v_{1}^{U-}\right],\left[\pi_{1}^{L-}, \pi_{1}^{U-}\right]\right)\right\rangle,\left\langle C_{2},\left(\left[\mu_{2}^{L-}, \mu_{2}^{U-}\right],\left[v_{2}^{L-}, v_{2}^{U-}\right],\left[\pi_{2}^{L-}, \pi_{2}^{U-}\right]\right)\right\rangle \ldots \ldots \ldots . .\left\langle C_{n},\left(\left[\mu_{n}^{L-}, \mu_{n}^{U-}\right],\left[v_{n}^{L-}, v_{n}^{U-}\right],\left[\pi_{n}^{L-}, \pi_{n}^{U-}\right]\right)\right\rangle\right\}
$$

Step 6: To determine the distance between alternative $X i$, IVSF-PIS and IVSF-NIS used, respectively. The normalized distance formula of Peng and Yang (2016a, 2016b) used in this step.

Distance to IVSF-PIS:

$$
d\left(X_{i j}, X_{j}^{+}\right)=\frac{1}{4 n} \sum_{j=1}^{n}\left(\left|\left(u_{i j}^{L}\right)^{2}-\left(u_{j}^{+}\right)^{2}\right|+\left|\left(u_{i j}^{U}\right)^{2}-\left(u_{j}^{+}\right)^{2}\right|+\left|\left(v_{i j}^{L}\right)^{2}-\left(v_{j}^{+}\right)^{2}\right|+\left|\left(v_{i j}^{U}\right)^{2}-\left(v_{j}^{+}\right)^{2}\right|+\left|\left(\pi_{i j}^{L}\right)^{2}-\left(\pi_{j}^{+}\right)^{2}\right|+\left|\left(\pi_{i j}^{U}\right)^{2}-\left(\pi_{j}^{+}\right)^{2}\right| \mid \forall_{i}\right.
$$

Distance to IVSF-NIS:

$$
d\left(X_{i j}, X_{j}^{-}\right)=\frac{1}{4 n} \sum_{j=1}^{n}\left(\left|\left(u_{i j}^{L}\right)^{2}-\left(u_{j}^{-}\right)^{2}\right|+\left|\left(u_{i j}^{U}\right)^{2}-\left(u_{j}^{-}\right)^{2}\right|+\left|\left(v_{i j}^{L}\right)^{2}-\left(v_{j}^{-}\right)^{2}\right|+\left|\left(v_{i j}^{U}\right)^{2}-\left(v_{j}^{-}\right)^{2}\right|+\left|\left(\pi_{i j}^{L}\right)^{2}-\left(\pi_{j}^{-}\right)^{2}\right|+\left|\left(\pi_{i j}^{U}\right)^{2}-\left(\pi_{j}^{-}\right)^{2}\right| \mid \forall_{i}\right.
$$

Step 7: Calculating the closeness ratio:

$$
\text { ClosenessRatio }_{i}=\frac{d\left(X_{i j}, X_{j}^{-}\right)}{d\left(X_{i j}, X_{j}^{-}\right)+d\left(X_{i j}, X_{j}^{+}\right)}
$$

Step 8: Determine the optimal order of alternatives and determine the most appropriate alternative.

\section{A real case application using extension of TOPSIS method with interval-valued spherical fuzzy sets}

In the present study, the selection of roll stabilization system is evaluated around different alternatives and criteria. There are technical studies in the literature on the applicability and efficiency of alternative stabilizing systems for cruise ships. Therefore, in addition to technical evaluations, a different perspective is created for the problem with many criteria determined. The criteria were evaluated through a two-stage questionnaire containing comparative questions by a group of three decision-makers (DM1, DM2, DM3) including captain, academician and designer. The weights of these decision-makers having different experience levels were determined as $0.3,0.2$ and 0.5 , respectively. The identified criteria are clearly stated in Table 2 together with their explanations. Based on these criteria, four types of roll motion stabilization system (A1 Active Anti-roll tanks, A2 Activated Fins, A3 Gyroscopic Roll Stabilizer and A4 Bilge Keels) were evaluated. Figure 1 shows the relationship between criteria and alternatives according to the TOPSIS method. 


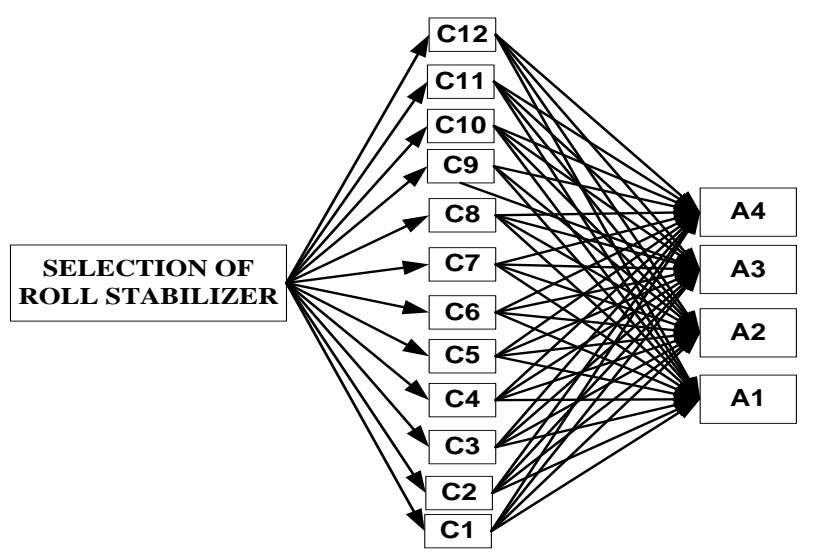

Fig 1. Hierarchical structure for selection of roll stabilizer systems

Table 2 Definitions of defined criteria for roll stabilizer selection problem (Sellars and Martin, 1992; Balin, 2020)

\begin{tabular}{lll}
\hline No & Criteria & Definition \\
\hline C1 & Initial cost & $\begin{array}{l}\text { Required investment cost for stabilizer } \\
\text { system }\end{array}$
\end{tabular}

C2 Maintenance cost

C3 Maintenance Requirements
The total value of the costs such as required auxiliary equipment and workmanship in maintenance work

Standards, certification works and approval processes to be used in maintenance and repair works

C4 Effect on Hull Resistance and Speed The status on the performance of the ship

C5

Effect of Crew Performance and The comfort of the crew in operational Passenger Comfort

C6 Ease of Repair

C7 Underwater Noise

C8 Roll Reduction

C9 Working on Wide Speed Range

C10 Installation Requirements

C11 Reaction Time

C12 Risk of Damage activities and the mobility of passengers

Complexity of the structure of the stabilizer system

Effect of noise and vibration level generated by stabilizer system

Percentage of minimizing amplitude of roll motion

Ability to operate at different speeds of stabilizer system

Ease of placement and positioning of the stabilizer system

Speed of effect and response of stabilizer system

Damage to activities such as berthing due to the position of the stabilizer system 
A novel fuzzy multi-criteria decision-making

Hakan Demirel

methodology based upon the spherical fuzzy sets for stabilizer selection of cruise ships

All evaluations given in Table 3 in the form of a decision matrix, which collected and combined using the IVSWAM operator shown in the equation 2, taking into consideration the weight of the decision-makers.

Table 3 Aggregated decision matrix.

\begin{tabular}{lllll}
\hline & A1 & A2 & A3 & A4 \\
\hline C1 & $([0.12,0.17],[0.82,0.92],[0.09,0.171])$ & $([0.32,0.41],[0.53,0.63],[0.26,0.335])$ & $([0.84,0.94],[0.11,0.16],[0.07,0.156])$ & $([0.74,0.84],[0.16,0.21],[0.156,0.206])$ \\
C2 & $([0.7,0.8],[0.18,0.23],[0.18,0.227])$ & $([0.84,0.94],[0.11,0.16],[0.07,0.156])$ & $([0.67,0.76],[0.23,0.28],[0.2,0.262])$ & $([0.15,0.2],[0.74,0.84],[0.155,0.205])$ \\
C3 & $([0.31,0.36],[0.58,0.69],[0.24,0.315])$ & $([0.15,0.2],[0.76,0.88],[0.14,0.203])$ & $([0.65,0.75],[0.2,0.25],[0.2,0.251])$ & $([0.58,0.65],[0.33,0.41],[0.255,0.339])$ \\
C4 & $([0.16,0.23],[0.75,0.87],[0.15,0.215])$ & $([0.32,0.38],[0.56,0.66],[0.25,0.327])$ & $([0.77,0.86],[0.19,0.25],[0.15,0.224])$ & $([0.7,0.8],[0.18,0.23],[0.177,0.227])$ \\
C5 & $([0.13,0.18],[0.79,0.91],[0.11,0.187])$ & $([0.36,0.46],[0.45,0.54],[0.25,0.299])$ & $([0.79,0.89],[0.13,0.18],[0.12,0.182])$ & $([0.72,0.82],[0.17,0.22],[0.166,0.218])$ \\
C6 & $([0.24,0.34],[0.56,0.66],[0.24,0.295])$ & $([0.48,0.56],[0.4,0.49],[0.28,0.362])$ & $([0.85,0.95],[0.1,0.15],[0.05,0.15])$ & $([0.65,0.75],[0.2,0.25],[0.202,0.251])$ \\
C7 & $([0.12,0.17],[0.82,0.92],[0.09,0.171])$ & $([0.12,0.17],[0.82,0.92],[0.09,0.171])$ & $([0.72,0.82],[0.17,0.22],[0.16,0.217])$ & $([0.65,0.72],[0.33,0.42],[0.23,0.331])$ \\
C8 & $([0.14,0.19],[0.76,0.87],[0.14,0.196])$ & $([0.22,0.29],[0.61,0.71],[0.22,0.269])$ & $([0.81,0.91],[0.12,0.17],[0.1,0.172])$ & $([0.65,0.75],[0.2,0.25],[0.202,0.251])$ \\
C9 & $([0.35,0.43],[0.51,0.6],[0.21,0.263])$ & $([0.57,0.64],[0.35,0.44],[0.26,0.351])$ & $([0.12,0.17],[0.81,0.91],[0.1,0.176])$ & $([0.62,0.71],[0.25,0.31],[0.226,0.287])$ \\
C10 & $([0.74,0.84],[0.16,0.21],[0.16,0.206])$ & $([0.65,0.74],[0.24,0.3],[0.21,0.276])$ & $([0.84,0.94],[0.11,0.16],[0.07,0.156])$ & $([0.69,0.79],[0.18,0.23],[0.184,0.233])$ \\
C11 & $([0.71,0.81],[0.17,0.22],[0.17,0.222])$ & $([0.17,0.25],[0.72,0.85],[0.17,0.23])$ & $([0.81,0.91],[0.12,0.17],[0.1,0.172])$ & $([0.65,0.76],[0.2,0.25],[0.199,0.255])$ \\
C12 & $([0.53,0.61],[0.35,0.43],[0.27,0.354])$ & $([0.4,0.48],[0.47,0.56],[0.21,0.264])$ & $([0.79,0.89],[0.13,0.18],[0.12,0.182])$ & $([0.79,0.89],[0.13,0.18],[0.12,0.184])$ \\
\hline
\end{tabular}

The weight of each criteria obtained using the IVSWAM operator shown in the equation 2, expressing the importance of the criteria determined by the DMs, is given in Table 4.

Table 4 Aggregated criteria weight.

\begin{tabular}{ll}
\hline Criteria & \multicolumn{1}{c}{ Weight } \\
\hline C1 & $([0.2,0.26],[0.64,0.74],[0.2,0.25])$ \\
C2 & $([0.1,0.15],[0.84,0.94],[0.06,0.16])$ \\
C3 & $([0.8,0.9],[0.13,0.18],[0.11,0.18])$ \\
C4 & $([0.53,0.61],[0.35,0.43],[0.27,0.35])$ \\
C5 & $([0.2,0.26],[0.64,0.74],[0.2,0.25])$ \\
C6 & $([0.85,0.95],[0.1,0.15],[0.05,0.15])$ \\
C7 & $([0.21,0.27],[0.73,0.86],[0.17,0.24])$ \\
C8 & $([0.12,0.17],[0.81,0.91],[0.1,0.18])$ \\
C9 & $([0.36,0.43],[0.51,0.6],[0.2,0.26])$ \\
C10 & $([0.4,0.5],[0.42,0.51],[0.26,0.32])$ \\
C11 & $([0.76,0.86],[0.15,0.2],[0.14,0.2])$ \\
C12 & $([0.84,0.94],[0.11,0.16],[0.07,0.16])$ \\
\hline After
\end{tabular}

After determining the weights of the criteria and the rating of the alternatives, the spherical fuzzy decision matrix with the weighted range-value given in Table 5 was formed using equation 3.

Table 5 Weighted decision matrix.

\begin{tabular}{llllll}
\hline & A1 & A2 & A3 & A4 \\
\hline C1 & $([0.02,0.04],[0.9,0.97],[0.14,0.14])$ & $([0.07,0.1],[0.76,0.85],[0.26,0.29])$ & $([0.17,0.24],[0.65,0.75],[0.21,0.27])$ & $([0.15,0.22],[0.65,0.75],[0.23,0.28])$ \\
C2 & $([0.07,0.12],[0.85,0.95],[0.11,0.16])$ & $([0.09,0.15],[0.84,0.95],[0.07,0.16])$ & $([0.07,0.12],[0.85,0.95],[0.12,0.17])$ & $([0.02,0.03],[0.93,0.98],[0.09,0.1])$ \\
C3 & $([0.25,0.33],[0.59,0.7],[0.26,0.33])$ & $([0.12,0.18],[0.77,0.88],[0.15,0.21])$ & $([0.52,0.68],[0.24,0.3],[0.23,0.3])$ & $([0.46,0.59],[0.35,0.44],[0.27,0.37])$ \\
C4 & $([0.08,0.14],[0.78,0.9],[0.23,0.25])$ & $([0.17,0.23],[0.63,0.73],[0.32,0.38])$ & $([0.41,0.52],[0.39,0.48],[0.3,0.39])$ & $([0.37,0.49],[0.39,0.47],[0.31,0.39])$ \\
C5 & $([0.03,0.05],[0.88,0.96],[0.15,0.16])$ & $([0.07,0.12],[0.73,0.83],[0.26,0.28])$ & $([0.16,0.23],[0.65,0.75],[0.22,0.27])$ & $([0.15,0.21],[0.65,0.76],[0.24,0.28])$ \\
C6 & $([0.21,0.32],[0.57,0.67],[0.25,0.31])$ & $([0.41,0.53],[0.41,0.51],[0.28,0.38])$ & $([0.72,0.9],[0.14,0.21],[0.07,0.21])$ & $([0.56,0.72],[0.22,0.29],[0.21,0.29])$ \\
C7 & $([0.02,0.05],[0.92,0.98],[0.11,0.12])$ & $([0.02,0.05],[0.92,0.98],[0.11,0.12])$ & $([0.15,0.23],[0.74,0.87],[0.2,0.25])$ & $([0.14,0.2],[0.77,0.89],[0.22,0.26])$ \\
C8 & $([0.02,0.03],[0.92,0.98],[0.11,0.11])$ & $([0.03,0.05],[0.88,0.96],[0.15,0.16])$ & $([0.1,0.16],[0.81,0.92],[0.12,0.18])$ & $([0.08,0.13],[0.82,0.92],[0.15,0.19])$ \\
C9 & $([0.13,0.18],[0.67,0.77],[0.25,0.29])$ & $([0.21,0.28],[0.59,0.69],[0.29,0.35])$ & $([0.04,0.08],[0.86,0.95],[0.15,0.17])$ & $([0.22,0.31],[0.55,0.65],[0.27,0.33])$ \\
C10 & $([0.29,0.42],[0.45,0.54],[0.29,0.35])$ & $([0.26,0.37],[0.48,0.57],[0.31,0.37])$ & $([0.33,0.47],[0.44,0.53],[0.26,0.34])$ & $([0.27,0.39],[0.46,0.55],[0.3,0.36])$ \\
C11 & $([0.54,0.69],[0.22,0.29],[0.22,0.29])$ & $([0.13,0.21],[0.73,0.85],[0.19,0.24])$ & $([0.61,0.78],[0.19,0.26],[0.17,0.25])$ & $([0.5,0.65],[0.25,0.32],[0.24,0.31])$ \\
C12 & $([0.44,0.57],[0.36,0.45],[0.28,0.37])$ & $([0.33,0.45],[0.48,0.57],[0.21,0.29])$ & $([0.66,0.83],[0.17,0.24],[0.14,0.23])$ & $([0.66,0.83],[0.17,0.24],[0.14,0.24])$ \\
\hline
\end{tabular}


Score function values according to Table 5 are obtained as in Table 6 using equation 4. The highest values represent PIS and the lowest values represent NIS.

Table 6 Score function values.

\begin{tabular}{lllll}
\hline Criteria & A1 & A2 & A3 & A4 \\
\hline C1 & 0.89 & 0.73 & 0.59 & 0.60 \\
C2 & 0.84 & 0.83 & 0.84 & 0.93 \\
C3 & 0.59 & 0.74 & 0.51 & 0.54 \\
C4 & 0.78 & 0.63 & 0.53 & 0.50 \\
C5 & 0.88 & 0.69 & 0.60 & 0.60 \\
C6 & 0.54 & 0.55 & 0.72 & 0.54 \\
C7 & 0.92 & 0.92 & 0.74 & 0.78 \\
C8 & 0.92 & 0.88 & 0.79 & 0.80 \\
C9 & 0.62 & 0.58 & 0.85 & 0.52 \\
C10 & 0.48 & 0.50 & 0.49 & 0.48 \\
C11 & 0.52 & 0.71 & 0.59 & 0.49 \\
C12 & 0.54 & 0.50 & 0.65 & 0.65 \\
\hline
\end{tabular}

Table 7 shows the Interval-valued Spherical Fuzzy Positive Ideal Solution and Interval-valued Spherical Fuzzy Negative Ideal Solution corresponding to the best and worst scores obtained in Table 6 using equation 5 to 10 respectively.

Table 7 IVSF-PIS and IVSF-NIS.

\begin{tabular}{lll}
\hline & \multicolumn{1}{c}{ IVSF-PIS } & \multicolumn{1}{c}{ IVSF-NIS } \\
\hline C1 & $([0.02,0.04],[0.9,0.97],[0.14,0.14])$ & $([0.07,0.1],[0.76,0.85],[0.26,0.29])$ \\
C2 & $([0.02,0.03],[0.93,0.98],[0.09,0.1])$ & $([0.09,0.15],[0.84,0.95],[0.07,0.16])$ \\
C3 & $([0.12,0.18],[0.77,0.88],[0.15,0.21])$ & $([0.52,0.68],[0.24,0.3],[0.23,0.3])$ \\
C4 & $([0.08,0.14],[0.78,0.9],[0.23,0.25])$ & $([0.37,0.49],[0.39,0.47],[0.31,0.39])$ \\
C5 & $([0.03,0.05],[0.88,0.96],[0.15,0.16])$ & $([0.16,0.23],[0.65,0.75],[0.22,0.27])$ \\
C6 & $([0.72,0.9],[0.14,0.21],[0.07,0.21])$ & $([0.21,0.32],[0.57,0.67],[0.25,0.31])$ \\
C7 & $([0.02,0.05],[0.92,0.98],[0.11,0.12])$ & $([0.15,0.23],[0.74,0.87],[0.2,0.25])$ \\
C8 & $([0.02,0.03],[0.92,0.98],[0.11,0.11])$ & $([0.1,0.16],[0.81,0.92],[0.12,0.18])$ \\
C9 & $([0.04,0.08],[0.86,0.95],[0.15,0.17])$ & $([0.22,0.31],[0.55,0.65],[0.27,0.33])$ \\
C10 & $([0.26,0.37],[0.48,0.57],[0.31,0.37])$ & $([0.27,0.39],[0.46,0.55],[0.3,0.36])$ \\
C11 & $([0.13,0.21],[0.73,0.85],[0.19,0.24])$ & $([0.5,0.65],[0.25,0.32],[0.24,0.31])$ \\
C12 & $([0.66,0.83],[0.17,0.24],[0.14,0.23])$ & $([0.33,0.45],[0.48,0.57],[0.21,0.29])$ \\
\hline
\end{tabular}

As the next step of the methodology, the values giving the distances between alternative $X_{i}$ and the IVSF-PIS as well as IVSF-NIS and the closeness ratios values were calculated and ranked in Table 8 and Table 9, respectively using equation 11. Table 8 and Table 9 demonstrated that Activated Fins chosen as the most appropriate alternatives with the 0.690 $\mathrm{CR}$ value as the common opinion of all subject-matter-experts, where Bilge Keels determined as the last option with the $0.451 \mathrm{CR}$ value. Gyroscopic Roll Stabilizer and Active Anti-roll tanks ranked as the second and third alternative with 0.560 and $0.489 \mathrm{CR}$ value, respectively. 
Table 8 Distances to interval-valued positive and negative ideal solutions and Closeness ratio of each alternative.

\begin{tabular}{lllll}
\hline Alternatives & A1 & A2 & A3 & A4 \\
\hline PIS & 0.141 & 0.127 & 0.187 & 0.200 \\
NIS & 0.135 & 0.282 & 0.238 & 0.164 \\
CR & 0.489 & 0.690 & 0.560 & 0.451 \\
\hline
\end{tabular}

Table 9 Ranking to interval-valued positive and negative ideal solutions and closeness ratio of each alternative.

\begin{tabular}{lllll}
\hline Alternatives & A1 & A2 & A3 & A4 \\
\hline IV-PIS & 2 & 1 & 3 & 4 \\
IV-NIS & 4 & 1 & 2 & 3 \\
CR & 3 & 1 & 2 & 4 \\
\hline
\end{tabular}

IVSF-TOPSIS provides decision makers with a wider range of definitions to make their decisions. Considering the proximity ratio values of the proposed method, the best alternative is $\mathrm{A} 2$ and the overall ranking is $\mathrm{A} 2>\mathrm{A} 3>\mathrm{A} 1>\mathrm{A} 4$.

\section{CONCLUSION}

On cruising ships, the comfort and safety of passengers and crews is of critical importance. In this context, roll stabilization systems play an active role. While selecting these systems, it is decided by making evaluations on different alternatives. Alternative stabilization systems have advantages and disadvantages against each other. At this point, it is necessary to determine which criteria will be in the foreground while making a choice.

In this study, in order to determine the most effective stabilization system for cruise ships, a multi-criteria decision-making method such as interval-valued spherical fuzzy TOPSIS, based on the new theory, had been proposed. IVSF-TOPSIS offers decision makers a wider range of definitions in terms of making their decisions. In this context, experts evaluated in detail the active and passive roll stabilizer systems, which are alternatives to each other, taking into account many parameters from different perspectives. To this end, the proposed IVSFTOPSIS methodology is considered to be functional because it is realistic and reliable.

Among the alternative stabilizing systems evaluated by experts based on certain criteria, Activated fin system was identified as the most effective one. In addition to these assessments, it should be noted that the differentiation of experts and criteria, which is an important part of the problem, may change the outcome.

In future studies, alternatives and criteria evaluated in this study can be used for different types of ships, and comparisons can be made with different multi-criteria decision making methods (such as AHP and VIKOR) by changing the number of criteria, alternatives and experts.

\section{REFERENCES}

[1] Lloyd, A. R. J. M. (1989). Seakeeping: ship behaviour in rough weather. Ellis Horwood.

[2] 10. Parker, M.N. (1965). Brief review of ship stabilization systems. Naval Engineers Journal 77 (4), 640. https://doi.org/10.1111/j.1559-3584.1965.tb04994.x 
[3] 11. Smith, T. C. And Thomas W. L. (1990). A Survey of Ship Motion Reduction Devices. David Taylor Research Center. https://doi.org/10.21236/ADA229278

[4] Lewis, V.E., Editor, "Principles of Naval Architecture, Vol. III, Motions in Waves and Controllability," the Society of Naval Architects and Marine Engineers, Jersey City, N.J. (1989).

[5] Bell, J. and Walker, W.P., "Activated and Passive Controlled Fluid Tank System for Ship Stabilization," Transactions, Society of Naval Architects and Marine Engineers, Vol. 74, pp. 150-193 (1966).

[6] Perez, T., \& Steinmann, P. D. (2009). Analysis of ship roll gyrostabiliser control. IFAC Proceedings Volumes, 42(18), 310-315. https://doi.org/10.3182/20090916-3-BR-3001.0007

[7] Lee, S., Rhee, K. P., \& Choi, J. W. (2011). Design of the roll stabilization controller, using fin stabilizers and pod propellers. Applied Ocean Research, 33(4), 229-239. https://doi.org/10.1016/j.apor.2011.07.005

[8] Kim, J. H., \& Kim, Y. H. (2011). Motion control of a cruise ship by using active stabilizing fins. Proceedings of the Institution of Mechanical Engineers, Part M: Journal of Engineering for the Maritime Environment, 225(4), 311-324. https://doi.org/10.1177/1475090211421268

[9] Lee, S. K., Lee, J. H., Rhee, K. P., \& Choi, J. W. (2012). The Effect of the Turning Rate of the Pod Propeller on the Roll Control System of the Cruise Ship. Journal of the Society of Naval Architects of Korea, 49(1), 14-25. https://doi.org/10.3744/SNAK.2012.49.1.14

[10] Kim, J. H., \& Kim, Y. (2014). Time-domain analysis of passenger comfort on cruise ships under motion responses in waves. Proceedings of the Institution of Mechanical Engineers, Part M: Journal of Engineering for the Maritime Environment, 228(4), 331-347. https://doi.org/10.1177/1475090213486890

[11] Ye, X., Wang, X., Wang, Y., Luo, Y., Yang, G., \& Sun, R. (2019). Design Features and Construction Enlightenments of Oasis-Class Luxury Cruise Ships. In Report on the Development of Cruise Industry in China (2018) (pp. 201-218). Springer, Singapore. https://doi.org/10.1007/978-981-13-3780-2_11

[12] Kafalı, M., Özkök, M. (2015). Evaluation of shipyard selection criteria for shipowners using a fuzzy technique. Journal of Marine Engineering \& Technology. 14(3), pp. 146-158. https://doi.org/10.1080/20464177.2015.1118787

[13] Sellers, F.H., Martin, J.P. (1992). Selection and evaluation of ship roll stabilization systems. Marine Technology 29 (2), 84-101.

[14] Demirel, H., Balin, A., Çelik. E., Alarçin, F. (2018). A Fuzzy AHP and ELECTRE Method for Selecting Stabilizing Device in Ship Industry. Brodogradnja. 69(3), pp. 61-77. https://doi.org/10.21278/brod69304

[15] Gong, Z., Xu, X., Yang, Y., Zhou, Y., \& Zhang, H. (2016). The spherical distance for intuitionistic fuzzy sets and its application in decision analysis. Technological and Economic Development of Economy, 22(3), 393-415. https://doi.org/10.3846/20294913.2016.1181684

[16] Ullah, K., Mahmood, T., \& Jan, N. (2018). Similarity measures for T-spherical fuzzy sets with applications in pattern recognition. Symmetry, 10(6), 193. https://doi.org/10.3390/sym10060193

[17] Hwang CL and Yoon K. 1981. Multiple attributes decision making methods and applications, Springer, Berlin. https://doi.org/10.1007/978-3-642-48318-9_3

[18] Ertuğrul I and Karakaşoğlu N. 2008. Comparison of fuzzy AHP and fuzzy TOPSIS methods for facility location selection. Int J Adv Manuf Technol 39:783-795 https://doi.org/10.1007/s00170-007-1249-8

[19] Gündoğdu, F. K., \& Kahraman, C. (2019a). A novel fuzzy TOPSIS method using emerging intervalvalued spherical fuzzy sets. Engineering Applications of Artificial Intelligence, 85, 307-323. https://doi.org/10.1016/j.engappai.2019.06.003

[20] Gündoğdu, F. K., \& Kahraman, C. (2019b). Spherical fuzzy sets and spherical fuzzy TOPSIS method. Journal of Intelligent \& Fuzzy Systems, (Preprint), 1-16.

[21] Gündoğdu, F. K., \& Kahraman, C. (2019c). A novel spherical fuzzy analytic hierarchy process and its renewable energy application. Soft Computing, 1-15.

[22] Kahraman, C., Gundogdu, F. K., Onar, S. C., \& Oztaysi, B. (2019, August). Hospital Location Selection Using Spherical Fuzzy TOPSIS. In 2019 Conference of the International Fuzzy Systems Association and the European Society for Fuzzy Logic and Technology (EUSFLAT 2019). Atlantis Press. https://doi.org/10.2991/eusflat-19.2019.12

[23] Peng, X., \& Yang, Y. (2016a). Fundamental properties of interval-valued Pythagorean fuzzy aggregation operators. International Journal of Intelligent Systems, 31(5), 444-487. https://doi.org/10.1002/int.21790

[24] Peng, X., \& Yang, Y. (2016b). Pythagorean fuzzy Choquet integral based MABAC method for multiple attribute group decision making. International Journal of Intelligent Systems, 31(10), 989-1020. https://doi.org/10.1002/int.21814 
[25] Ashraf, S., Abdullah, S., \& Mahmood, T. (2018). GRA method based on spherical linguistic fuzzy Choquet integral environment and its application in multi-attribute decision-making problems. Mathematical Sciences, 12(4), 263-275. https://doi.org/10.1007/s40096-018-0266-0

[26] Ashraf, S., Abdullah, S., Mahmood, T., Ghani, F., \& Mahmood, T. (2019a). Spherical fuzzy sets and their applications in multi-attribute decision making problems. Journal of Intelligent \& Fuzzy Systems, (Preprint), 1-16. https://doi.org/10.3233/JIFS-172009

[27] Ashraf, S., Abdullah, S., Mahmood, T., Ghani, F., \& Mahmood, T. (2019b). Spherical fuzzy sets and their applications in multi-attribute decision making problems. Journal of Intelligent \& Fuzzy Systems, 36(3), 2829-2844. https://doi.org/10.3233/JIFS-172009

[28] Ashraf, S., Abdullah, S., \& Mahmood, T. (2019c). Spherical fuzzy Dombi aggregation operators and their application in group decision making problems. Journal of Ambient Intelligence and Humanized Computing, 1-19.

[29] Ashraf, S., Abdullah, S., \& Abdullah, L. (2019d). Child development influence environmental factors determined using spherical fuzzy distance measures. Mathematics, 7(8), 661. https://doi.org/10.3390/math7080661

[30] Sellars, F. H., \& Martin, J. P. (1992). Selection and evaluation of ship roll stabilization systems. Marine Technology and SNAME News, 29(02), 84-101.

[31] Balin, A. (2020). (1910-5508) A novel fuzzy multi-criteria decision-making methodology based upon the spherical fuzzy sets with a real case study. Iranian Journal of Fuzzy Systems.

Submitted: $\quad$ 16.10.2019 $\quad$ Asisst. Prof. Hakan Demirel, hakandemirel@beun.edu.tr

Accepted: $\quad$ 15.07.2020. 